\title{
Long-range oriented graphene-like nanosheets with corrugated structure
}

DOI:

10.1039/C8CC07678B

\section{Document Version}

Accepted author manuscript

Link to publication record in Manchester Research Explorer

\section{Citation for published version (APA):}

He, D., Xue, W. D., Li, Z., Marsden, A. J., Prestat, E., Hu, W., Zhao, R., \& Bissett, M. A. (2018). Long-range oriented graphene-like nanosheets with corrugated structure. Chemical Communications, 54, 13543-13546. https://doi.org/10.1039/C8CC07678B

\section{Published in:}

Chemical Communications

\section{Citing this paper}

Please note that where the full-text provided on Manchester Research Explorer is the Author Accepted Manuscript or Proof version this may differ from the final Published version. If citing, it is advised that you check and use the publisher's definitive version.

\section{General rights}

Copyright and moral rights for the publications made accessible in the Research Explorer are retained by the authors and/or other copyright owners and it is a condition of accessing publications that users recognise and abide by the legal requirements associated with these rights.

\section{Takedown policy}

If you believe that this document breaches copyright please refer to the University of Manchester's Takedown Procedures [http://man.ac.uk/04Y6Bo] or contact uml.scholarlycommunications@manchester.ac.uk providing relevant details, so we can investigate your claim.

\section{OPEN ACCESS}




\section{Accepted Manuscript}

This article can be cited before page numbers have been issued, to do this please use: D. He, W. D. Xue, Z. Li, A. J. Marsden, E. Prestat, W. Hu, R. Zhao and M. A. Bissett, Chem. Commun., 2018, DOI:
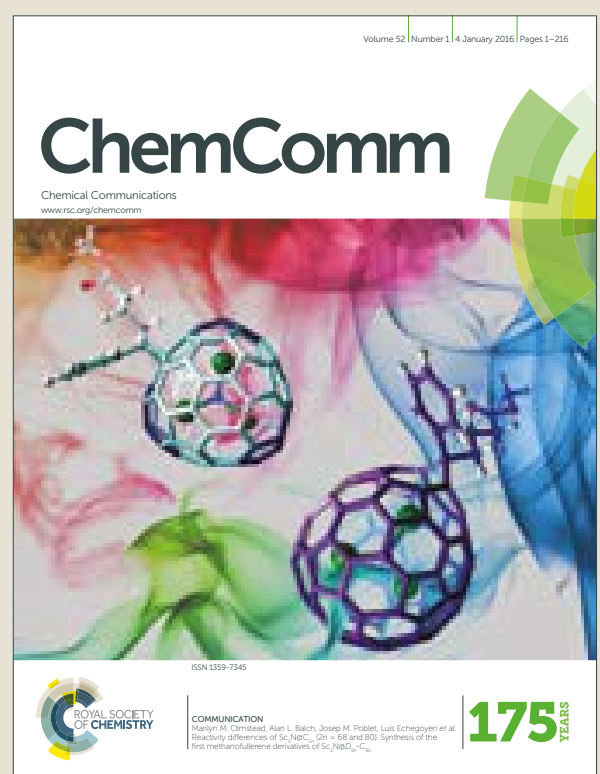

This is an Accepted Manuscript, which has been through the Royal Society of Chemistry peer review process and has been accepted for publication.

Accepted Manuscripts are published online shortly after acceptance, before technical editing, formatting and proof reading. Using this free service, authors can make their results available to the community, in citable form, before we publish the edited article. We will replace this Accepted Manuscript with the edited and formatted Advance Article as soon as it is available.

You can find more information about Accepted Manuscripts in the author guidelines.

Please note that technical editing may introduce minor changes to the text and/or graphics, which may alter content. The journal's standard Terms \& Conditions and the ethical guidelines, outlined in our author and reviewer resource centre, still apply. In no event shall the Royal Society of Chemistry be held responsible for any errors or omissions in this Accepted Manuscript or any consequences arising from the use of any information it contains. 


\section{COMMUNICATION}

\section{Long-range Oriented and Corrugated Structure of the Graphene- like Nanosheets}

Received 00th January 20xx, Accepted 00th January 20xx

DOI: $10.1039 / \times 0 \times x 00000 x$
Dongxu He${ }^{a}$, Weidong Xue ${ }^{a}$, Zheling Li ${ }^{b}$, Alexander J. Marsden ${ }^{b}$, Eric Prestat ${ }^{b, c}$, Wencheng Hua ${ }^{a}$ Rui Zhao $^{\mathrm{a}^{*}}$, and Mark A. Bissett ${ }^{\mathrm{b}}$

www.rsc.org/

\begin{abstract}
A facile molten-salt (MS) route for the scalable synthesis of freestanding, long-range oriented and corrugated graphene-like sheets from a copper phthalocyanine (CuPc) precursor is reported. Their unique arrangement and transformation behavior in molten potassium chloride $(\mathrm{KCl})$ play a key role in promoting the successful synthesis of the anisotropic nanostrucure.
\end{abstract}

The nanoscale morphology of carbon materials strongly influences their physical and chemical properties. ${ }^{1,2}$ The complex interplay between their atomic arrangement, electronic properties, and nanoscale morphology have received considerable attention for two dimensional carbon materials. ${ }^{3-}$ 6 For example, Bao and co-workers used the thermally generated strains to create periodic ripples with a controlled orientation, amplitude and wavelength. ${ }^{2}$ A vertical thermal fluctuation can also result in a corrugated morphology which enables graphene to be thermodynamically stable and possess a periodicity of about $8 \mathrm{~nm} .{ }^{7}$ Also, a series of long-range ordered structures produced from block copolymer precursors have been designed and realized by Matyjaszewski et $a l^{8}$ including: a well-organized nanostructured carbon array, ${ }^{9}$ densely grafted brushes, ${ }^{10}$ and long-range ordered thin films with the thickness range from $100 \mathrm{~nm}$ to $1 \mu \mathrm{m} .{ }^{11}$ Building these structures of nanometer width can be remarkably done and with angstromlevel control, but when extending these nanoscale structures to long-range layers, the chemical coupling reactions are often insufficient to maintain the required degrees of polymerization. ${ }^{12}$

In this work, we present a facile approach to produce longrange oriented and corrugated graphene-like nanosheets (GNS) by pyrolysis of (CuPc) via a molten $\mathrm{KCl}$ system. The unique

a. Institute of Applied Electrochemistry, School of Materials And Energy, University of Electronic Science and Technology of China, Chengdu 610054, PR China. E-mail: ruizhao@uestc.edu.cn

b. School of Materials, National Graphene Institute, University of Manchester, Oxford Road, M13 9PL Manchester, U.K.

c. SuperSTEM Laboratory, SciTech Daresbury Campus, WA4 4AD Warrington, U.K.

+ Electronic Supplementary Information (ESI) available: See DOI: $10.1039 / \mathrm{x} 0 \mathrm{xx} 00000 \mathrm{x}$ interaction between CuPc and $\mathrm{KCl}$ resulted in a herringbonetype molecular arrangement and it further transformed into nano-corrugated structure. We aim to achieve a better understanding of the growth mechanism and surface morphology of the produced $\mathrm{N}$-doped heterostructure and internal nanostructure of the GNS.

The schematic of the MS process used in this work is shown in Figure 1a. Wet chemistry methods performed in solutions provide an ideal reaction environment and sufficient reversible dynamics. The use of MS as the reaction medium emerged as a significant complementary strategy to conventional liquid phase synthesis and to broaden the operational temperature to over $1000{ }^{\circ} \mathrm{C} .{ }^{13-15}$ Copper phthalocyanine (CuPc), as shown in Figure $1 \mathrm{~b}$, is a planar organic macromolecule where the central copper atom is covalently bonded with two nitrogen atoms of the porphyrin ring and also linked with two nitrogen atoms of the same rings. The symmetry of the molecule, due to a lack a dipole moment and a completely conjugated structure, contributes to its exceptional stability. Almost all the planar CuPc molecules can be arranged in a face-to-face stack, but the

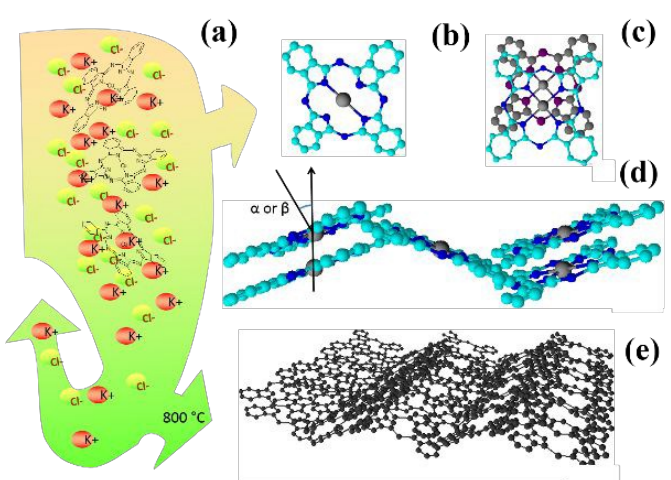

Figure 1. (a) Schematic showing the MS method ( $\mathrm{KCl}$ system) used. (b) Structural model of CuPc molecule. Stacking arrangement of $\alpha$-CuPc ((c): top view; (d) side view). (e) 3D illustration of the $1 \mathrm{KCl}-\mathrm{GNS}$ structure. 
stacking overlay of the adjacent molecules and relative arrangements are different. The two different stacking types are named $\alpha$ and $b$ referring to the difference in the angle between the axis perpendicular and in-plane of the stacks (corresponding to $\alpha$ and $B$ phases are $26.5^{\circ}$ and $46.8^{\circ}$, respectively). As shown in Figure $\mathrm{S} 1$, there are four possible stacking arrangements of $\alpha$-CuPc and 8 -CuPc. ${ }^{16}$

Grown on an alkali halide substrate, the two-dimensional arrangement of different Pc molecules are different from one another. $\mathrm{KCl}$ is the most suitable substrate for the preparation of highly ordered Pc epitaxial films. ${ }^{17}$ As shown in Figure $1 \mathrm{~d}$, both $\alpha$-CuPc and 6 -CuPc have a herringbone-type molecular arrangement between the columns. ${ }^{16}$ But $\alpha$-CuPc has a larger overlap with neighboring molecules within each molecular column and this relates to a larger lattice constant. It should be noted that, (i) the copper atom at the center of each molecule is coordinated with the nitrogen atoms of the adjacent molecules and forms a distorted octahedral geometry; (ii) the $\pi$ electrons in one molecule and the peripheral hydrogen atoms of the molecules in adjacent stacks are in close proximity which results in a stabilized crystal lattice of the B-CuPc. Multiple works have indicated that their phase transformation can be achieved by thermal treatment. ${ }^{18,19}$ Therefore, during the pyrolysis process shown in Figure 1 a, from $\sim 250{ }^{\circ} \mathrm{C},{ }^{18} \alpha$-CuPc will undergo a phase transition to $B$-CuPc. Then, the more stabilized B-CuPc will deposit on the well-matched $\mathrm{KCl}$ substrate with a herringbone-type molecular arrangement as shown in Figure 1d.
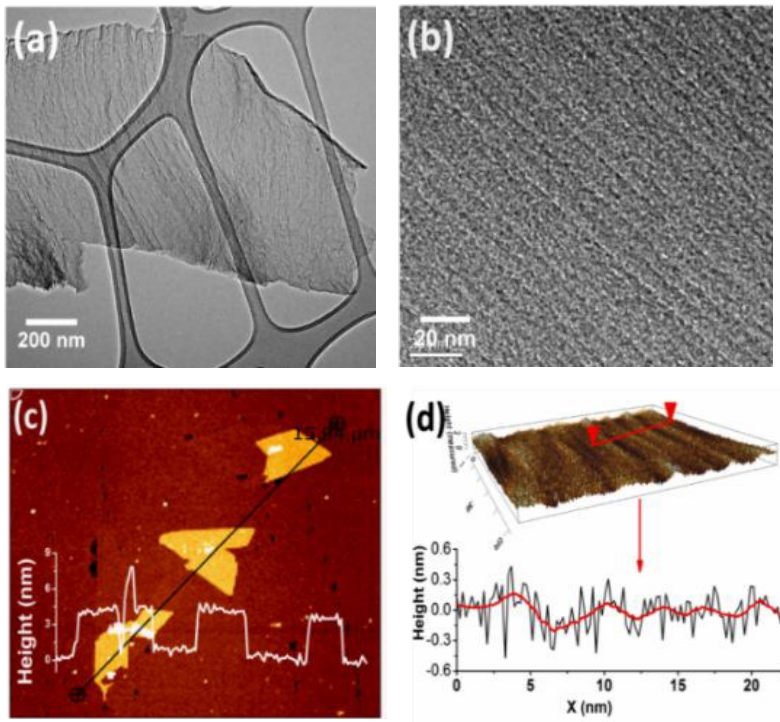

Figure 2. (a) Typical TEM image of $1 \mathrm{KCl}-\mathrm{GNS}$; (b) high-resolution TEM image of a local area on $1 \mathrm{KCl}-\mathrm{GNS}$; (c) and (d) are the AFM images of $1 \mathrm{KCl}-\mathrm{GNS}$.

Importantly, the growth mechanism of CuPc on alkali halide substrates has been studied and a combination of three factors shown that $\mathrm{KCl}$ is the best substrate for its regular arrangement: (i) a higher strength of electrophilic interaction which is following the degree of ionic strength of the substrates; (ii) a higher strength of net interaction which refers to the distance between the electron-attracting cations and the opposite azo- bridging nitrogen atoms; and (iii) the growth axis symmetsy ipf the $\mathrm{KCl}$ substrate favorably directs theolposs916pecerystafliee growth directions. ${ }^{16,17,20}$ Therefore, the carbon geometry will possibly maintained during the pyrolysis process because of their exceptional stability and regular arrangement. Furthermore, samples synthesized at a wide temperature from $600{ }^{\circ} \mathrm{C}$ to $900^{\circ} \mathrm{C}$ or with different molten salt system have been studied and supported our inference (Figure S2 and Figure S3). The obtained products were denoted by $\mathrm{xKCl-GNS}$, where $\mathrm{x}$ refers to the percentage of $\mathrm{CuPc}$ in the precursor. Figure 2 presents TEM and AFM characterization for the $1 \mathrm{KCl}-\mathrm{GNS}$. Figure 2a shows clearly that CuPc was converted into thin sheets. Notably, a long-ranged regular corrugation was found on the surface. With a higher magnification in Figure $2 b$, a periodic ripple-like morphology was observed with a periodicity of $\sim 5 \mathrm{~nm}$. The thickness of the layer can be further confirmed with AFM analysis. As shown in Figure $2 \mathrm{c}$ and $2 \mathrm{~d}$, a smallest thickness value of $3.5 \mathrm{~nm}( \pm 0.3 \mathrm{~nm})$ was observed for $1 \mathrm{KCl}-\mathrm{GNS}$. Additionally, measurements with more than ten different flakes indicate that the majority of the flakes have the thickness ranging from $2.0 \mathrm{~nm}$ to $4.5 \mathrm{~nm}$. Topography of the $1 \mathrm{KCl}-\mathrm{GNS}$ nanosheets was presented by the 3D AFM image in Figure 2d, where an ordered surface fluctuation can be observed which matches well with the ripple in Figure $2 b$.

Scanning transmission electron microscopy (STEM) imaging combined with Electron energy-loss spectroscopy (EELS) are powerful tools to analyze the microstructure of a material. Figure 3a shows a bright field STEM (BFSTEM) image of the synthesized graphene-like flake and inset is the corresponding selected area diffraction (SAED) of the flake. The diffraction rings are consistent with polycrystalline graphene. ${ }^{21}$ Another dark field STEM (DFSTEM) image in Figure $3 b$ further illustrates the morphology of one flake which is suspended on the lacey carbon support and shows oriented nano-corrugations (as highlighted in the figure) and a micro-scale wavy terrain. Furthermore, a high resolution BFSTEM image of the edge is shown in Figure $3 c$ to confirm the multilayer structure of the flakes. The interlayer spacing inside the material is $3.6 \pm 0.2 \AA$, suggesting a graphitic-like structure. Figure $3 e$ and $3 f$ presented the magnified images of Figure $3 d$, showing the stacked flake with steps across it. Low loss EELS was used to obtain the thickness map using the log ratio method (see Methods for more detail). The height of the steps is $4 \mathrm{~nm}$, and this matches well with the AFM data presented above. The EELS maps of a stacked flake was further investigated in Figure $3 \mathrm{~g}, 3 \mathrm{~h}$ and $3 \mathrm{i}$. Each terrace displays a uniform elemental distribution. These results match well with the thickness of the thin flake and indicate that the most stable phase of the assembled CuPc precursor is probably about ten layers (see Figure $3 c$ ). The uniform C (Figure $3 \mathrm{~g}$ ) and $\mathrm{N}$ (Figure $3 \mathrm{~h}$ ) distribution is consistent with its formation from Pc molecules. Additionally, Figure $3 i$ shows the oxygen distribution and its increased presence at the terrace steps can be attributed to chemisorbed oxygen species. XRD and XPS analyzes of the sample were carried out to obtain a better understanding of the synthesized materials composition in Figure S4. 
Polarized Raman spectroscopy has been further used for a better understanding of the nanostructure of the layer. As previously demonstrated, ${ }^{22,23}$ within the spot size $(\sim 2 \mu \mathrm{m})$ of the Raman laser graphene can be regarded as crystallographically 'isotropic' ${ }^{24}$ hence the Raman band intensity stays constant regardless of the angle between the polarization of $_{\text {A }}$ the laser and the crystallographic orientation of thegrapherae. Howevep, the presence of anisotropy in the structure, e.g. corrugations and edges, leads to a change in its polarizability tensor, which further causes the Raman band intensity varying as the angle

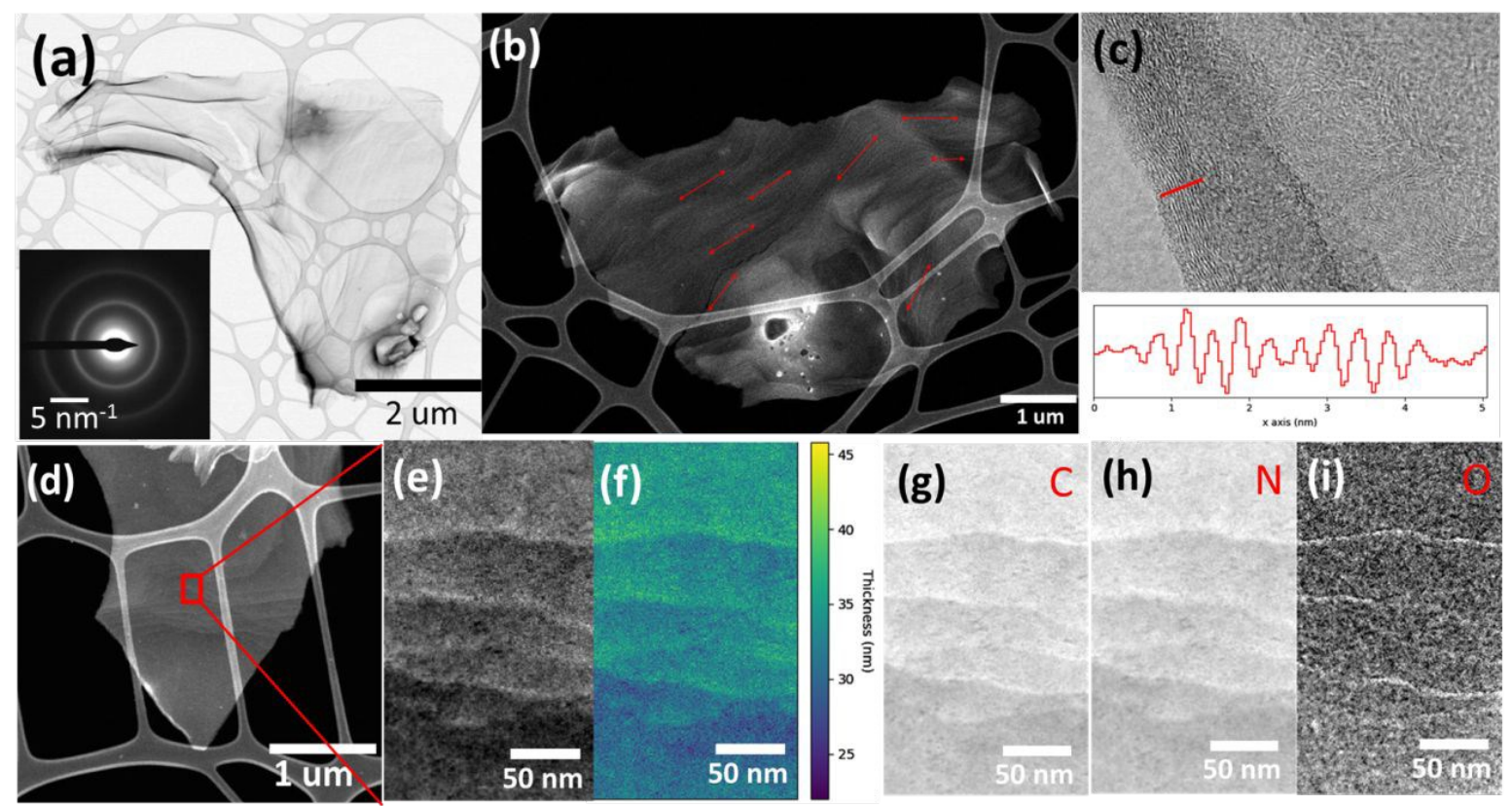

Figure 3. (a) BF-STEM image of $1 \mathrm{KCl}-$ GNS flake (inset is the corresponding SAED); (b) HAADF-STEM image of a $1 \mathrm{KCl}-\mathrm{GNS}$ flake; (c) is the high resolution STEM image of the edge (inset is the height profile across the edge); (d) and (e) are magnified local area images of one stacked flake; (f) is a thickness map from the same area and $(\mathrm{g})$, $(\mathrm{h})$ and $(\mathrm{i})$ are the elemental maps of $\mathrm{C}, \mathrm{N}$ and $\mathrm{O}$, respectively.

between the directions of the edge and the laser polarization. 22,23 As shown above in the STEM (Figure 3), the nanocorrugations are uniformly distributed over the graphene-like sheet unidirectionally. The Raman spectra of one graphene-like sheet are shown in Figure $\mathrm{S} 5$. It can be seen that the $I_{\mathrm{G}}$ reaches the maximum when the Raman laser polarization is at $70^{\circ}$ to the corrugation direction; while minimum when the angle is around $160^{\circ}$. The curve fitting to obtain the $I_{\mathrm{G}}$ is also shown as the inset. To interpret this, the structure is regarded as the analogy of an array of carbon nanotubes that lie along the direction of the corrugation (Figure 1e). As demonstrated earlier, ${ }^{25}$ the Raman band intensity shows strong dependence of the axial direction of carbon nanotubes, where a maximum presents when the incident Raman laser polarization is parallel to the carbon nanotube axis while minimum when they are perpendicular, as below:

$I_{\mathrm{G}}=A \cos ^{2}\left(\theta-\theta_{\mathrm{o}}\right)+B$

where $\vartheta$ is angle between the laser polarization and the corrugation direction and $\vartheta_{0}$ is the offset of $\vartheta$ that denotes the angel of the corrugation direction. On this basis, several graphene flakes of $1 \mathrm{KCl}-\mathrm{GNS}$ have been tested, the variation of the normalized $I_{\mathrm{G}}$ as the function of angle $\vartheta$ is shown in Figure 4. The degrees of corrugation can be characterized by the ratio of $A /(A+B)-R$ (Eq.1), where the higher the $R$ value the heavier of the corrugation. ${ }^{23}$ The extreme would be $A=0$ and $B=1$ for completely flat graphene but as the graphene starts to corrugate, the anisotropy increases, thus the value of $A$ increases. It can be seen from Figure $4 a, 8 b, 8 c$ and $8 d$ that all of the four flakes have a minimum intensity around $0.7-0.8$, but the one in Figure 4a has the highest degree of corrugation, while the one in Figure 4c being the flattest. It is noted that the $I_{G}$ variation in (Figure $4 \mathrm{~d}$ ) does not quite follow the behavior as the other three do, and it is thought to be due to the defective layers are stacked in the third dimension and form a thick layer, the corrugation of the adjacent layers can hardly keep the same orientation and thus an irregular corrugation presents (Figure $4 d$ ). Apart from the variation of $I_{G}$, the position of $G$ band $\omega_{G}$, as well shows the angular dependence on $\vartheta$, as shown as the blue dots in Figure 4. Although very scattered, the $\omega_{\mathrm{G}}$ is nearly $90^{\circ}$ out of phase of the variation of $I_{\mathrm{G}}$. This is because the Raman band position will upshift as compression while downshift for tension. ${ }^{26}$ It can be found the $\omega_{\mathrm{G}}$ reaches high wavenumber, corresponding to compression, when $I_{\mathrm{G}}$ is about the minimum, implying at the transverse direction of the corrugation the graphene is compressed, further confirming the model that is proposed above.

To summarize, all the spectral analysis and the morphology characterizations have strongly supported our suggested model about the formation of the rippled $\mathrm{N}$-doped graphene-like sheets. With a reasonable thermal treatment process, CuPc tends to arrange into purified $\beta$-phase columns, and the columns then form thin layered herringbone-type arrangements in molten $\mathrm{KCl}$. Also, the molten $\mathrm{KCl}$ not only 
provides a homogenous liquid reactant environment but also 1
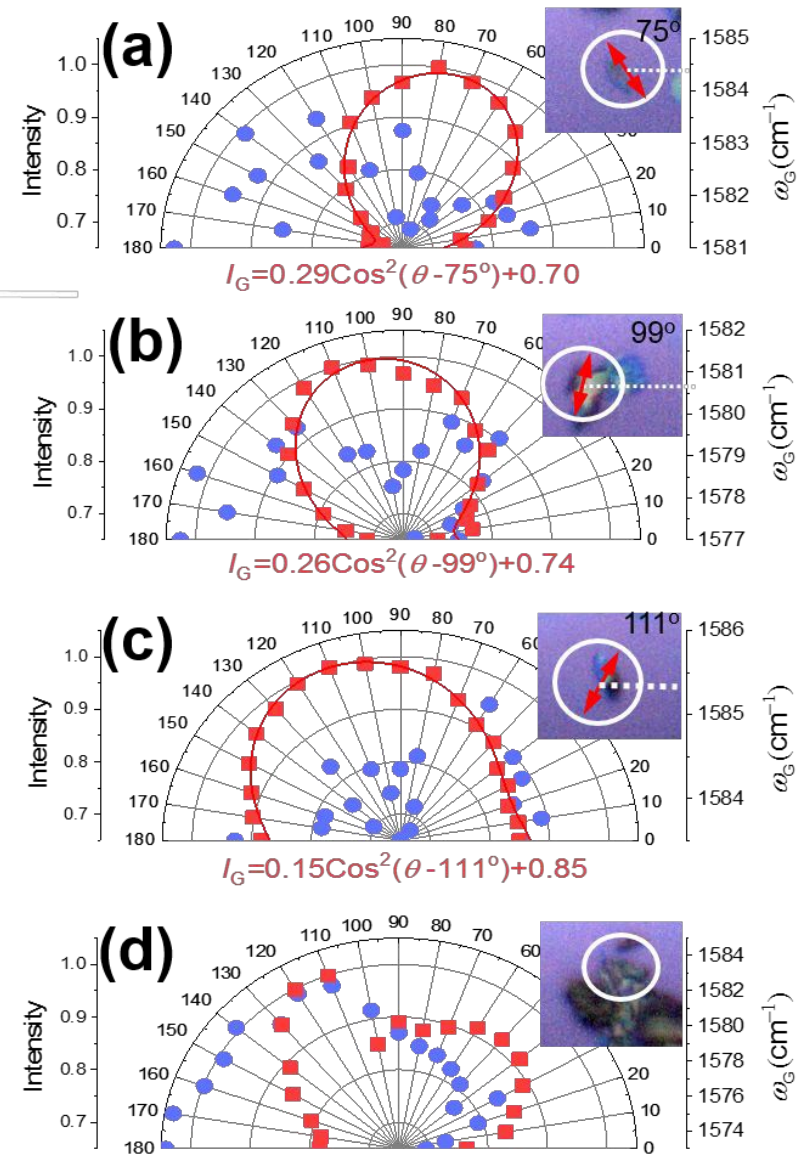

inhibits layer restacking. The material displays exceptional

Figure 4. (a)(b)(c)(d) Variation of $\mathrm{I}_{\mathrm{G}}$ (red dots) and $\omega_{\mathrm{G}}$ (blue dots) as function of $\vartheta$ of four graphene-like sheets (red dots). The red curves are the fitting using Eq.1, and the fitted functions are indicated. Top right are the optical micrographs of the four samples of $1 \mathrm{KCl}-\mathrm{GNS}$. The white circles indicate where the test has been taken and the white dashed lines and red arrows indicate the reference direction and the corrugation directions, respectively. All the scale bars (the length of the micrographs) are $10 \mu \mathrm{m}$.

stability, despite the dehydrogenation and denitrogenation processes happening simultaneously during the pyrolysis procedure the corrugated $\beta$-CuPc arrangement maintain its backbone, and thus the long-range corrugated graphene-like layers were formed. As the insufficient of dynamics will always restricted the further polymerization or physical modulation, the facile strategy presented here provided a good alternative for fabricating the long-range, well-defined and free-standing periodic nanostructure.

\section{Conflicts of interest}

There are no conflicts to declare.

\section{Notes and references}

L. Tapasztó, T. Dumitrica, S. J. Kim, P. Nemes-Inczzert Ele Online Hwang and L. P. Biró, Nat. Phys., 2012, :8,073997742.CC07678B W. Bao, F. Miao, Z. Chen, H. Zhang, W. Jang, C. Dames and C. N. Lau, Nat. Nanotechnol., 2009, 4, 562-566.

T. Iwasaki, H. J. Park, M. Konuma, D. S. Lee, J. H. Smet and U. Starke, Nano Lett., 2011, 11, 79-84. J. Červenka and C. F. J. Flipse, Phys. Rev. B - Condens. Matter Mater. Phys., 2009, 79, 1-5. Y. Liu and B. I. Yakobson, Nano Lett., 2010, 10, 2178-2183. O. V. Yazyev and S. G. Louie, Nat. Mater., 2010, 9, 806-809. A. Fasolino, J. H. Los and M. I. Katsnelson, Nat. Mater., 2007, 6, 858-861.

J. P. Mcgann, M. Zhong, E. K. Kim, S. Natesakhawat, M. Jaroniec, J. F. Whitacre, K. Matyjaszewski and T.

Kowalewski, Chem. Synth. Appl. graphene carbon Mater., 2016, 1-19.

T. Kowalewski, N. V. Tsarevsky and K. Matyjaszewski, J. Am. Chem. Soc., 2002, 124, 10632-10633.

C. Tang, B. Dufour, T. Kowalewski and K. Matyjaszewski, Macromolecules, 2007, 40, 6199-6205.

C. Tang, A. Tracz, M. Kruk, R. Zhang, D. M. Smilgies, K. Matyjaszewski and T. Kowalewski, J. Am. Chem. Soc., 2005, 127, 6918-6919.

J. M. Tour, Chem. Mater., 2014, 26, 163-171.

X. Liu, C. Giordano and M. Antonietti, Small, 2014, 10, 193200.

J. Wang, B. Ding, X. Hao, Y. Xu, Y. Wang, L. Shen, H. Dou and X. Zhang, Carbon N. Y., 2016, 102, 255-261.

W. D. Xue and R. Zhao, New J. Chem., 2014, 38, 2993 2998.

A. Hoshino, Y. Takenaka and H. Miyaji, Acta Crystallogr. Sect. B Struct. Sci., 2003, 59, 393-403.

H. Tada, K. Saiki and A. Koma, Jpn. J. Appl. Phys., 1991, 30, L306-L308.

M. Müller, R. E. Dinnebier, M. Jansen, S. Wiedemann and C. Plüg, Powder Diffr., 2009, 24, 191

S. I. Shihub and R. D. Gould, Thin Solid Films, 1996, 290 291, 390-394.

H. Hoshi, A. J. Dann and Y. Maruyama, J. Appl. Phys., 1990, 67, 6871-6875.

P. Y. Huang, C. S. Ruiz-Vargas, A. M. Van Der Zande, W. S. Whitney, M. P. Levendorf, J. W. Kevek, S. Garg, J. S. Alden, C. J. Hustedt, Y. Zhu, J. Park, P. L. McEuen and D. A. Muller, Nature, 2011, 469, 389-392.

Z. Li, R. J. Young, I. A. Kinloch, N. R. Wilson, A. J. Marsden and A. P. A. Raju, Carbon N. Y., 2015, 88, 215-224.

Z. Li, R. J. Young, N. R. Wilson, I. A. Kinloch, C. Vallés and Z. Li, Compos. Sci. Technol., 2016, 123, 125-133.

Z. Li, I. A. Kinloch, R. J. Young, K. S. Novoselov, G. Anagnostopoulos, J. Parthenios, C. Galiotis, K. Papagelis, C. Y. Lu and L. Britnell, ACS Nano, 2015, 9, 3917-3925.

G. S. Duesberg, I. Loa, M. Burghard, K. Syassen and S. Roth, Phys. Rev. Lett., 2000, 85, 5436-5439.

L. Gong, I. A. Kinloch, R. J. Young, I. Riaz, R. Jalil and K. S. Novoselov, Adv. Mater., 2010, 22, 2694-2697. 